EXTENDED REPORT

\title{
High production of proinflammatory and Th 1 cytokines by dendritic cells from patients with rheumatoid arthritis, and down regulation upon $\mathrm{F} c \gamma \mathrm{R}$ triggering
}

\author{
T R D J Radstake, P L E M van Lent, G J Pesman, A B Blom, F G J Sweep, J Rönnelid, G J Adema, \\ P Barrera, W B van den Berg
}

Ann Rheum Dis 2004;63:696-702. doi: 10.1136/ard.2003.010033

See end of article for authors' affiliations

Correspondence to:

Correspondence to:
Dr T R D J Radstake, Geert Grooteplein 8, $6500 \mathrm{HB}$

Niimegen, The

Netherlands; T.Radstake@ reuma.umen.nl

Accepted 30 June 2003

\begin{abstract}
Objective: To assess whether DC from RA produce altered cytokine levels and whether this is regulated by triggering of $\mathrm{Fc}$ gamma receptors $(\mathrm{F} c \gamma \mathrm{R})$.

Methods: The production of proinflammatory (TNF $\alpha$, ILI, IL6), Th1 (IL12, IFN $\gamma$ ), and Th2 (IL10) cytokine profiles of immature $D C$ (iDC) from patients with RA and healthy subjects upon triggering of $F c \gamma R$ dependent and independent pathways was investigated. IDC, derived from blood monocytes by standardised protocols, were stimulated with immune complexes (IC) at day 6 for 48 hours and, subsequently, for 2 days with LPS in the presence or absence of IC or IFN $\gamma$, resulting in fully matured DC (mDC). ILI, IL6, TNF $\alpha$, IFN $\gamma$, IL12, and IL10 levels in supernatants were measured by ELISA and RIA.

Results: $m D C$ from patients with RA showed a markedly increased production of ILI, IL6, TNF $\alpha$, and IL10 compared with $D C$ from healthy donors. Triggering of $F_{c} \gamma R$ decreased the production of proinflammatory cytokines ILI, ILI2, and IFN $\gamma$ by IDC and mDC in RA and controls. The production of IL6 and TNF $\alpha$ decreased in patients with RA, whereas it was increased in controls. Triggering of $F c \gamma R$ independent mechanisms using IFN $\gamma$ increased the production of proinflammatory and Thl cytokines, which was more pronounced in RA.

Conclusion: Fc $\gamma R$ dependent pathways influence cytokine production by DC. A skewed balance towards proinflammatory and Thl cytokines in RA can, at least partly, be restored by triggering $\mathrm{Fc \gamma R}$ on DC in RA. Insight into the mechanism which determines the $\mathrm{F} \gamma \gamma \mathrm{R}$ balance might lead to new strategies to abrogate Thl driven inflammatory processes in RA.
\end{abstract}

R heumatoid arthritis (RA) is a chronic autoimmune disease of unknown cause characterised by synovial inflammation and subsequent damage of cartilage and underlying bone. RA synovial tissue is infiltrated by activated macrophages, dendritic cells, and $\mathrm{T}$ cells and shows evident synovial hyperplasia and neoangiogenesis. Despite extensive research on the immunological mechanisms involved, the exact pathophysiological pathways remain unclear. It is currently well accepted that a complex system, in which numerous inflammatory cells, chemokines, and cytokines are implicated, dominates the inflammatory cascade of RA. Involvement of the cytokines tumour necrosis factor $\alpha$ $(\mathrm{TNF} \alpha)$, interleukin (IL) 1 , and IL6 has been studied thoroughly. The proinflammatory cytokines TNF $\alpha$ and ILl are crucial in RA and their neutralisation results in clinical and radiological improvement. ${ }^{12}$ Other cytokines regulate the balance between Th1 (IL12) and Th2 (IL10) immune reactions..$^{3-5}$ Both clinical and experimental evidence strongly suggests a cytokine balance skewed towards Thl responses in arthritis. ${ }^{6-8}$

Dendritic cells (DC) are professional antigen presenting cells which orchestrate innate and adaptive immune responses ${ }^{9}$ and have a critical role in the regulation of both peripheral and central tolerance. ${ }^{10}{ }^{11}$ In addition, DC are producers of large amounts of pro- and anti-inflammatory cytokines and chemokines which attract numerous effector cells to the site of inflammation. Nowadays, a large body of evidence points towards an important role for DC in both experimental arthritis ${ }^{12}$ and RA. ${ }^{13-17}$ Immature DC (iDC) are scattered throughout the body and are highly specialised for antigen uptake, which is mediated by several scavenger receptors including FC gamma receptors $(\mathrm{Fc} \gamma \mathrm{R}) .{ }^{18}{ }^{19}$ After antigen uptake or stimulation by proinflammatory cytokines, DC are triggered to undergo full maturation. This process is characterised by down regulation of the receptors involved in antigen uptake. ${ }^{20}$ We recently showed that DC obtained from patients with RA lack the normal down regulation of Fc $\gamma \mathrm{R}$ during maturation. ${ }^{15}$ Moreover, activated mature DC are abundantly present in synovial tissue from patients with RA and express high levels of Fc $\gamma$ RII in comparison with those of healthy subjects. ${ }^{14}{ }^{1521}$ These data underline the potential role of DC during inflammatory processes in RA, both systemically and locally.

Fc $\gamma R$ in humans can be divided into activation (Fc $\gamma$ RI, Fc $\gamma$ RIIa, and Fc $\gamma$ RIII) and inhibitory (Fc $\gamma$ RIIb) subtypes. ${ }^{22}{ }^{23}$ Fc $\gamma$ RII and Fc $\gamma$ RIII are mainly involved in the binding of IgGantigen complexes (immune complexes (IC)), which are abundantly present in RA. ${ }^{24}{ }^{25}$ The relevance of IC and the coordinated expression of activation and inhibitory Fc $\gamma \mathrm{R}$ in the activation of effector cells and experimental arthritis has been demonstrated in several studies. ${ }^{26-28}$ Of high interest are the results obtained recently from a study which examined the potential role for Fc $\gamma \mathrm{R}$ balance in the orchestration and polarisation of immune responses. ${ }^{29}{ }^{30}$ These studies clearly show that, depending on the balance between the opposing

Abbreviations: DC, dendritic cells; ELISA, enzyme linked immunosorbent assay; FACS, fluorescence activated cell sorter; $\mathrm{Fc} \gamma \mathrm{R}, \mathrm{Fc}$ gamma receptor; HAGGS, heat aggregated gamma immunoglobulins; IC, immune complexes; iDC, immature dendritic cells; IFN $\gamma$, interferon $\gamma$; IL, interleukin; LPS, lipopolysaccharide; $\mathrm{mDC}$, mature dendritic cells; RA rheumatoid arthritis; RIA, radioimmunoassay; $\mathrm{TNF} \alpha$, tumour necrosis factor $\alpha$ 
Fc $\gamma R$ subtypes, triggering by IC can lead to either maintenance of tolerance or initiation of immunity. Measurement of IL12 and IL10, two cytokines diametrically opposed in their action to instruct Th1/Th2 T cell profiles, suggested the importance of $\mathrm{F} c \gamma \mathrm{R}$ activation in the balance of these cytokines. The importance of the inhibitory Fc $\gamma \mathrm{R}$ subtype was further substantiated by the findings that only DC without an intact Fc $\gamma$ RIIb signalling pathway were able to show full maturation, activation, and T cell activation upon engagement of IC.

Taken together, these data are highly suggestive for a potential role for DC and Fc $\gamma$ R expression in the initiation and modulation of the inflammatory cascade during RA. Elucidation of the mechanisms responsible for the proinflammatory response and Thl cytokine balance in RA is a prerequisite to the development of effective immunomodulatory treatments for RA as has been shown with genetically modified DC during experimental arthritis. ${ }^{31}{ }^{32}$ In this study we therefore investigated the production of proinflammatory cytokines (ILl, TNF $\alpha$, and IL6), Thl (interferon (IFN) $\gamma$ and IL12) cytokines, and Th2 (IL10) cytokines by immature and fully mature DC under basal conditions and after stimulation via Fc $\gamma R$ dependent and independent pathways in RA. This study provides firm evidence that triggering of DC via Fc $\gamma R$ dependent pathways leads to a diminished production of IL6 and $\mathrm{TNF} \alpha$, which is specific for RA. Furthermore, triggering of FC $\gamma R$ down regulates production of IL12 whereas IL10 is clearly up regulated. These results may provide new clues for the therapeutic application of ex vivo "trained" DC to abrogate or diminish the Thl driven inflammatory process in RA.

\section{PATIENTS AND METHODS Patients}

A total of 26 patients with RA and 20 healthy controls were enrolled in the study. All patients fulfilled the American College of Rheumatology criteria ${ }^{33}$ for RA and gave informed consent for the study. All patients were treated with disease modifying antirheumatic drugs alone or in combination with non-steroidal anti-inflammatory drugs. Excluded from the study were patients who received treatment with systemic steroids or biological agents. The medical ethics committee of the University Medical Centre, Nijmegen approved the study protocol.

\section{Generation of monocyte derived DC}

Venous blood was collected in $10 \mathrm{ml}$ lithium heparin Vacutainer tubes (Becton \& Dickinson, Mountain View, CA) and the peripheral blood mononuclear cell fraction was obtained by density gradient centrifugation over FicollHypaque (Amersham Biosciences, Roosendaal, The Netherlands). After several stringent washing procedures the cells were allowed to adhere for 1 hour at $37^{\circ} \mathrm{C}$ in RPMI1640, Dutch modification (Life Technologies, Breda, The Netherlands), enriched with $2 \%$ heat inactivated human serum in six well culture plates (Costar, Badhoeverdorp, The Netherlands). Adherent monocytes were cultured in RPMI1640, Dutch modification, supplemented with 10\% heat inactivated fetal calf serum and antibiotic-antimycotic agent (Life Technologies) in the presence of $500 \mathrm{U} / \mathrm{ml}$ IL4 (Schering-Plough, Amstelveen, The Netherlands) and $800 \mathrm{U} / \mathrm{ml}$ granulocyte monocyte-colony stimulating factor (Schering-Plough) for 6 days. Fresh complete culture medium was added after 3 days.

At day 6 the iDC were harvested. To generate mDC, iDC were transferred to new six well culture plates and cultured for two more days in the presence of complete culture medium supplemented with $2 \mu \mathrm{g} / \mathrm{ml}$ lipopolysaccharide (LPS) (E coli, Sigma Chemicals, St Louis, MO). The expression of cell surface markers characterising both the iDC and mDC characteristics was checked by fluorescence activated cell sorter (FACS) techniques, as described previously..$^{15}$ Briefly, the first layer was attached after incubation of $1 \times 10^{5}$ monocyte derived DC for 30 minutes at $4{ }^{\circ} \mathrm{C}$ with the monoclonal antihuman antibodies against CDl4, CDl6, CD32, CD64 (all DAKO, Glostrup, Denmark); DC-SIGN, ${ }^{34}$ CD80 (Becton Dickinson); CD83 (Beckman Coulter, Mijdrecht, The Netherlands); CD86 (Pharmingen, San Diego, CA, USA); MHC-I (clone W6/32), MHC-II DQ (clone SPV-L3), and MHC-II DP/DR (clone Q1513). After a washing step, the cells were incubated with fluorescein isothiocyanate conjugated goat antimouse IgG for 30 minutes at $4{ }^{\circ} \mathrm{C}$ in complete darkness. Subsequently, the cells were washed and analysed by FACS techniques (Calibur, Becton \& Dickinson). Cells were gated according to their forward and side scattering patterns and the expression of DC-SIGN and CD83 for iDC and mDC, respectively. For each marker $10^{4}$ cells were counted in the gate. During all FACS procedures, mouse IgG2b was used as an isotype control and the same instrumental settings were used. In all FACS analyses, the amount and position of viable cells were controlled using propidium iodide staining.

\section{Fc $\gamma R$ dependent and independent stimulation of DC}

To investigate the effect of Fc $\gamma \mathrm{R}$ dependent or independent stimulation on cytokine production by iDC, fresh medium with or without heat aggregated gamma immunoglobulins (HAGGS, final concentration $100 \mu \mathrm{g} / \mathrm{ml}$ ) was added at day 6 and incubated for 48 hours. To study the effect of Fc $\gamma R$ triggering during DC maturation, iDC were stimulated with LPS on day 6 in the presence or absence of HAGGS for two more consecutive days. Fc $\gamma \mathrm{R}$ independent triggering of iDC and $\mathrm{mDC}$ was achieved by adding interferon gamma (IFN $\gamma$, final concentration $1000 \mathrm{U} / \mathrm{ml}$, Boehringer Ingelheim, Ingelheim am Rhein, Germany) in the same manner as with HAGGS. HAGGS were obtained by heating human IgG (Sigma Chemicals) at $63^{\circ} \mathrm{C}$ for 30 minutes. The solution was centrifuged at $12000 \mathrm{~g}$ for 10 minutes thereafter, and the concentration of HAGGS was determined by reading the absorbance at $280 \mathrm{~nm}$. Supernatants were collected at 48 hours depending on the assessment of iDC or DC during maturation, respectively. During the whole experiment, the same batch of heat inactivated fetal calf serum was used.

\section{Radioimmunoassay (RIA) for ILI}

Polyclonal antibodies for ILI $\beta$ were kindly provided by Sclavo (Siena, Italy). Human recombinant ILl $\beta$ was radiolabelled by the chloramine-T method. ${ }^{35}$ The RIA was performed as previously described. ${ }^{36}$ Briefly, all samples and standards were prepared and mixed with a standard buffer which contained $13 \mathrm{mM} \mathrm{Na}_{2}$ EDTA, $0.02 \%$ sodium azide, $0.25 \%$ bovine serum albumin (Boehring, Marburg, Germany), and inactivating units aprotinine, pH 7.4 (Bayer, Leverkussen, Germany). For measurement of IL1 $\beta$ in supernatants, $10 \mu \mathrm{l}$ of sample or standard was added to the buffer. The mixture was incubated for 1 day at room temperature. After the addition of tracer (about $7000 \mathrm{dpm} / 100 \mu \mathrm{l}$ ) the incubation was continued for two more days. Separation of bound and free tracer was achieved by the addition of $100 \mu \mathrm{l}$ of a separation agent containing sheep antirabbit IgG and $0.01 \%$ rabbit IgG (Sigma, St Louis, MO). After incubation for 30 minutes, the antibody complex was completely precipi-

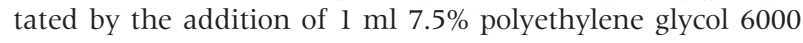
(Merck, Darmstadt, Germany). The range of the standard curve was $20-3000 \mathrm{pg} / \mathrm{ml}$, with a sensitivity of $40 \mathrm{pg} / \mathrm{ml}$. To minimise interassay variations, all samples from the same experiments were analysed in the same run in duplicate. The 


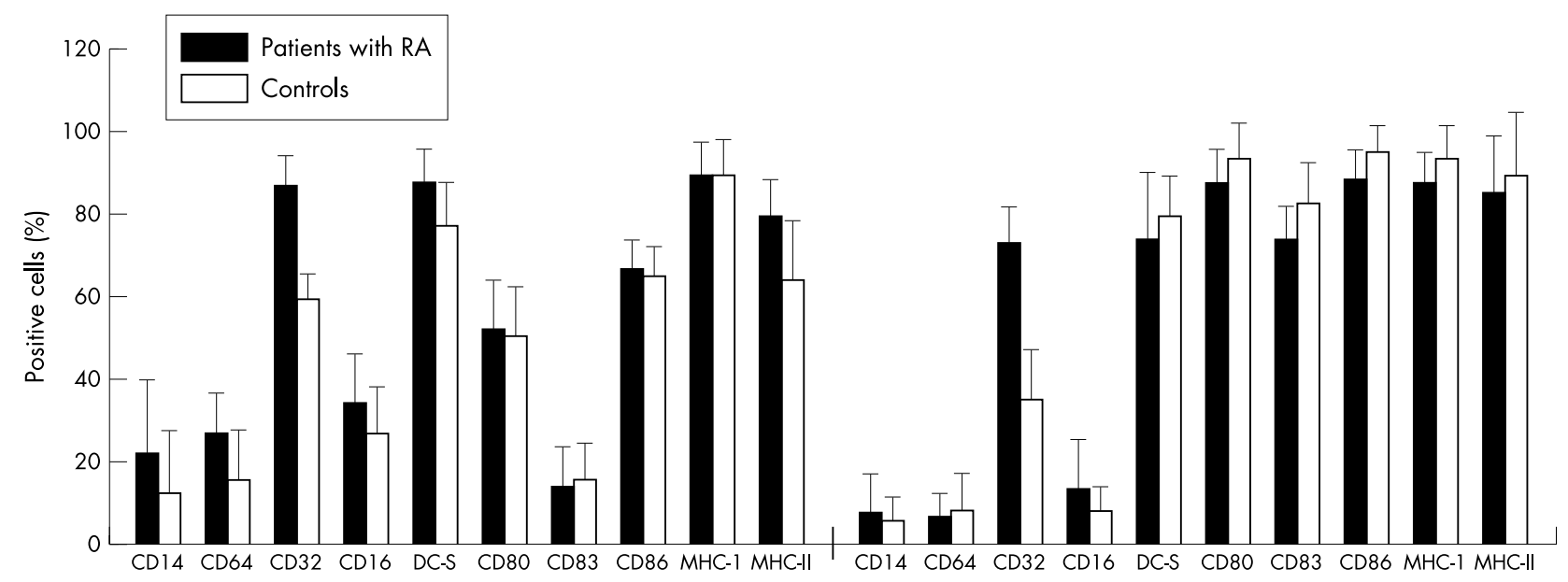

Immature DC

Mature DC

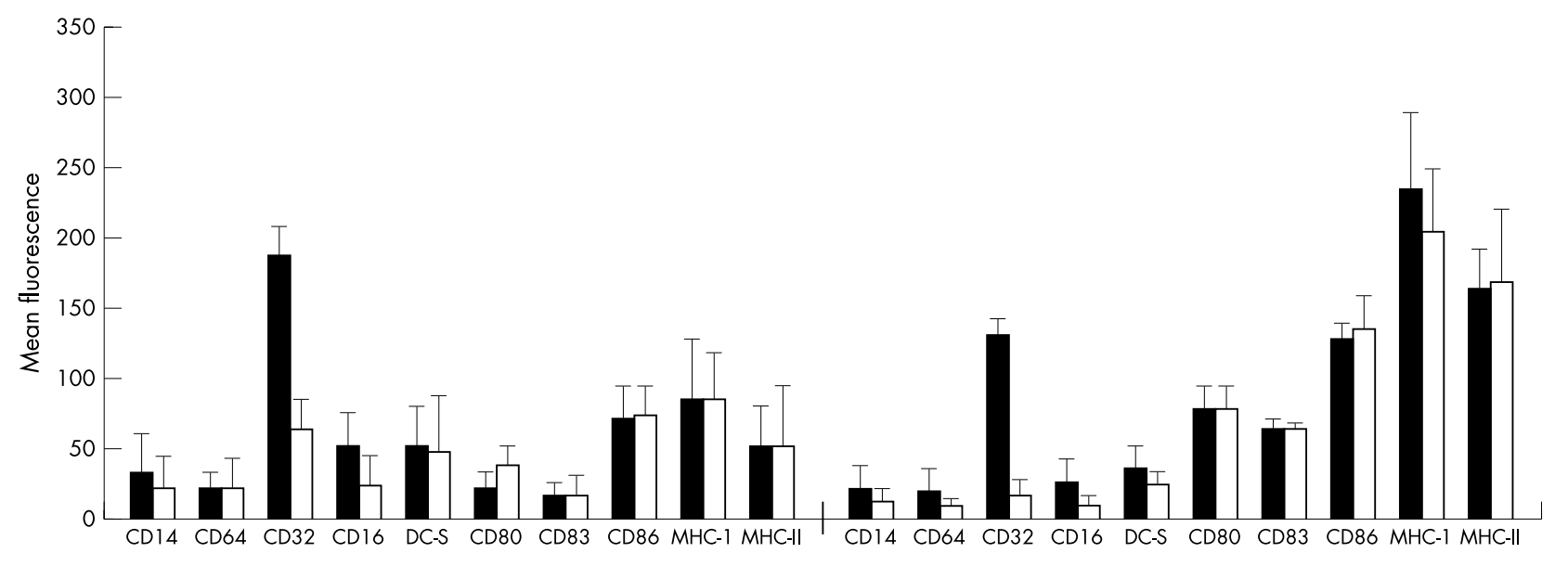

Immature DC

Mature DC

Figure 1 Characterisation of $\mathrm{IDC}$ and $\mathrm{mDC}$ phenotype by FACS analysis. The upper panel represents FACS analysis of the indicated markers and shows the percentage of positive cells. The lower panel represents the mean fluorescence of the marker corrected for isotype values. Each graph displays data from 26 patients with RA and 20 healthy subjects for both iDC and $\mathrm{mDC}$.

interassay variation of our RIA is estimated at $\leqslant 15 \%$, whereas the intra-assay variation is $\leqslant 10 \%$.

\section{Enzyme linked immunosorbent assay (ELISA) for IL6, IL 10, IL 12, and TNFa}

IL6 was measured by using a commercially available ELISA (Pelikine Compact human IL6 ELISA kit, CLB, Amsterdam, The Netherlands) according to the manufacturer's instructions. ${ }^{37}$ The lower limit of detection with this assay was $8 \mathrm{pg} /$ ml. IL10 (detection limit $3.9 \mathrm{pg} / \mathrm{ml}$ ) concentration was assessed by an ELISA, as described recently. ${ }^{38}$ In this system, a horseradish peroxidase system was used employing 3,3'5,5'-tetramethylbenzidine as substrate (DAKO, Glostrup, Denmark). As primary and secondary antibody 9D7 and 12G8, obtained from Pharmingen, were used respectively, at a concentration of $1 \mu \mathrm{g} / \mathrm{ml}$. The measurement of IL12p70 (detection limit $0.2 \mathrm{ng} / \mathrm{ml}$ ) was performed by a specific sandwich ELISA. As primary and secondary antibodies antihuman IL12p70 and biotin labelled antihuman IL12p40/ 70 were used, respectively (Endogen, Woburn, MA). A streptavidin-horseradish peroxidase conjugate was used to specifically stain the biotin labelled monoclonal antibodies and was visualised by incubation with 3,3'-5,5' -tetramethylbenzidine substrate. Absorption was measured at $450 \mathrm{~nm}$.
TNF $\alpha$ production was measured by an ELISA (detection limit $2 \mathrm{pg} / \mathrm{ml}$ ) using an experimental arrangement previously described for components of the plasminogen activator system. ${ }^{39}$

\section{Statistical analysis}

Differences between the DC from RA or healthy controls were calculated by the Mann-Whitney U test and Student's $t$ test, as appropriate. Values of $\mathrm{p}$ were two sided and the level of significance was set at $\mathrm{p}<0.05$.

\section{RESULTS}

Flow cytometric characterisation of immature and mature $D C$

Figure 1 shows the results of the FACS analysis of a panel of membrane markers on iDC and mDC. As expected, iDC express high levels of Fc $\gamma$ R II and DC-SIGN, intermediate levels of Fc $\gamma$ RI and III, costimulatory (CD80 and CD86) and MHC molecules, and low levels of CDI4 (the monocyte marker) and CD83 (mDC marker). Upon full maturation, DC clearly reflect an up regulation of costimulatory molecules CD83 and MHC, while the expression of FC $\gamma$ RI, II, and IIIa and CDI4 clearly decreased. As demonstrated before, ${ }^{15}$ for the majority of markers, no differences were seen between the 

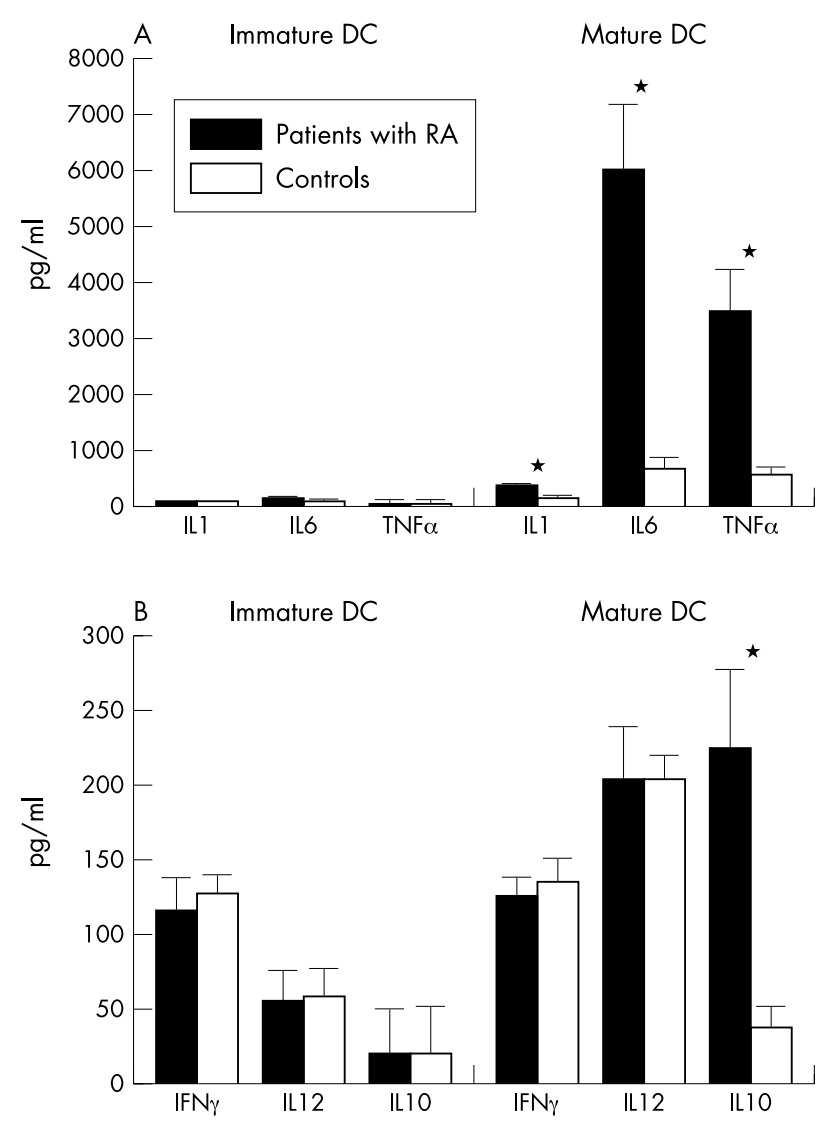

Figure 2 Production of pro- and anti-inflammatory cytokines by iDC and $\mathrm{mDC}$ from patients with RA and healthy controls. (A) Production of proinflammatory cytokines (pg/ml) IL l, IL6, TNF $\alpha$ by iDC and $\mathrm{mDC}$ from 26 patients with RA and 20 healthy subjects. (B) Th1 (IFN $\gamma$, IL12) and Th2 (IL10) cytokine production by iDC and $\mathrm{mDC}$ from the same group of patients with RA and healthy donors.

two groups for either the number of expressing cells (\%) or the mean fluorescence intensity. Interestingly, a clear difference in expression of Fc $\gamma \mathrm{R}$ was seen (fig 1). Comparison of the two groups showed a significantly increased Fc $\gamma$ RII (CD32) expression (mean fluorescence intensity) on immature DC from patients with RA $(\mathrm{n}=26)$ when compared with that of controls $(\mathrm{n}=20)(186(22) v 63$ (21) (mean $(S D), p=0.002$ ). Double staining procedures for CD83 and CD32 were performed to assess the percentage of mDC after LPS stimulation and to study the level of CD32 expression on CD83 positive cells. Fully matured DC from patients with RA expressed significantly higher levels of CD32 than those of healthy subjects (452 (58) v 188 (69), $\mathrm{p}<0.005)$. Furthermore, double staining of DC stimulated with LPS, confirmed that $86 \%$ of the cells were fully matured.

\section{Cytokine production by $\mathrm{IDC}$ and $\mathrm{mDC}$ from patients with RA and healthy controls}

We first investigated the production of proinflammatory (ILl, IL6, and TNF $\alpha$ ), Th1 (IFN $\gamma$, IL12), and Th2 (IL10) cytokines by iDC at day 6 and after full maturation with LPS (mDC, day 8) from 21 patients with RA and 18 healthy donors. Figures $2 \mathrm{~A}$ and $\mathrm{B}$ show that iDC from patients with RA and from healthy subjects produced similar levels of proinflammatory, Thl and Th2 cytokines. As expected, stimulation of iDC with LPS significantly increased the production of ILI, IL6, and TNFa in both groups. However, comparison of patients and controls showed clearly higher levels of IL1 (mean (SD); 341 (47) $v 116$ (7) pg/ml; $\mathrm{p}=0.005)$, IL6 (6027

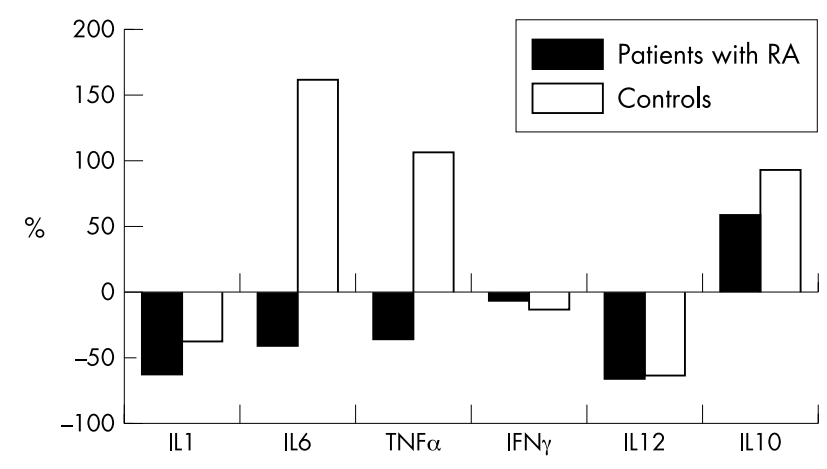

Figure $3 \quad F_{c} \gamma R$ dependent stimulation with anti-lgG complexes (IC) and effects on the production of proinflammatory, Th1, and Th2 cytokines by mature DC. The figure shows the percentage change in cytokine production of iDC cocultured with LPS and HAGGS compared with that of iDC cocultured with LPS alone from 15 patients with RA and 15 healthy donors.

( 1185$) v 661(220) \mathrm{pg} / \mathrm{ml} ; \mathrm{p}<0.005)$, and TNF $\alpha$ (3494 (762) $v$ 587 (128); $\mathrm{p}<0.005)$ in RA. Fully matured DC produced higher levels of IL12 and similar levels of IFN $\gamma$ than iDC, and there were no differences between patients with RA and healthy controls (fig 2B). In contrast, the production of IL10 was significantly higher in mDC from patients with RA (225 (53) $v 38$ (15) $\mathrm{pg} / \mathrm{ml} ; \mathrm{p}=0.003$ ) than in healthy subjects.

\section{Triggering of $F c \gamma R$ results in distinct cytokine responses between patients with RA and healthy controls}

Because previous findings from our group suggested that DC from patients with RA have an increased expression of inhibitory Fc $\gamma$ RIIb, ${ }^{15}$ we decided to test its repercussions on the production of cytokines. Therefore Fc $\gamma \mathrm{R}$ were triggered with heat aggregated IgG immunoglobulins (HAGGS).

As expected, the addition of HAGGS to DC from healthy controls cocultured with LPS before maturation significantly increased production of TNF $\alpha(110 \%, p=0.006)$ and IL6 $(160 \%, p=0.002)$ in comparison with DC cocultured with LPS alone (fig 3). In contrast, additional Fc $\gamma \mathrm{R}$ triggering of DC from patients with RA reduced the production of these cytokines with TNF $\alpha(-38 \%, \mathrm{p}=0.03)$ and IL6 $(-40 \%$, $\mathrm{p}=0.03)$. After Fc $\gamma \mathrm{R}$ stimulation, the production of ILI decreased both in DC from patients with RA (-63\%, $\mathrm{p}=0.008)$ and from healthy donors $(-38 \%, \mathrm{p}<0.005)$. The secretion of IFN $\gamma(-8 \% v-14 \%)$ and IL12 $(-67 \% v-65 \%)$ decreased equally in patients with RA and healthy donors, respectively, but was significant for only the latter.

The production of IL10 increased significantly upon Fc $\gamma \mathrm{R}$ dependent stimulation by DC from patients with RA $(57 \%$, $\mathrm{p}=0.01)$ and healthy controls $(92 \%, \mathrm{p}<0.01)$. Although the level of IL10 was already high in MDC of patients with RA (fig 3) it further increased to 354 (44) $\mathrm{pg} / \mathrm{ml} v 73$ (16) pg/ml $(p<0.005)$ in controls.

Because the expression of Fc $\gamma \mathrm{R}$ changes during DC maturation we also investigated the effect of Fc $\gamma R$ engagement by IC on cytokine production by iDC. The production of IL1, IL6, TNF $\alpha$, and IFN $\gamma$ by iDC was similar to that by mDC after triggering of Fc $\gamma \mathrm{R}$ in both patients with RA and healthy controls, whereas opposite reactions were observed for IL12 and ILIO (table 1).

\section{Cytokine production by DC stimulated via Fc $\gamma \mathrm{R}$ independent pathways (IFN $\gamma$ )}

Table 2 shows that the addition of IFN $\gamma$ to iDC dramatically increased production of IL6 (48-fold), TNF $\alpha$ (84-fold), and IL12 (82-fold) by DC from patients with RA and led to much higher levels of these cytokines in RA than in control DC. 

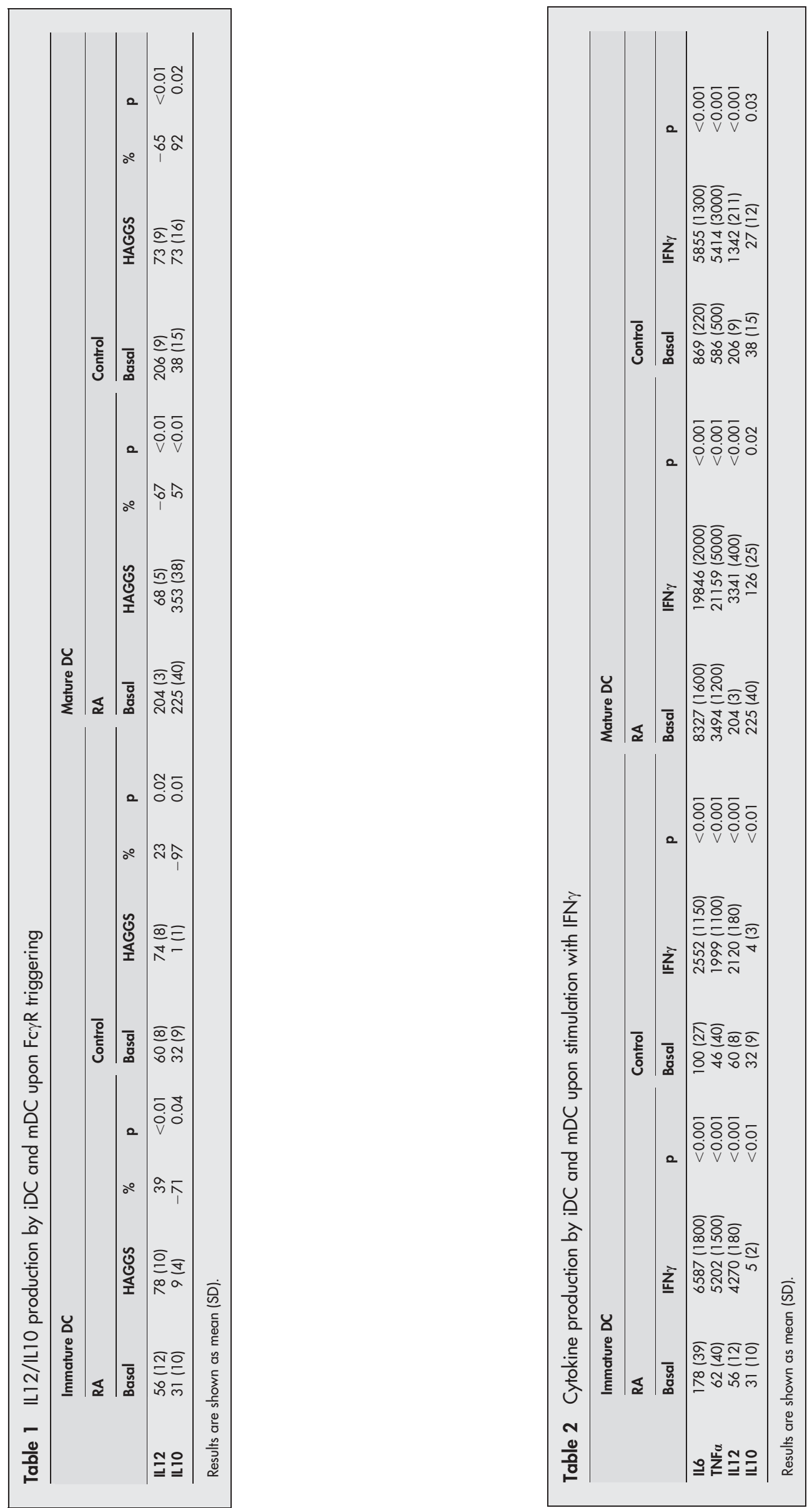

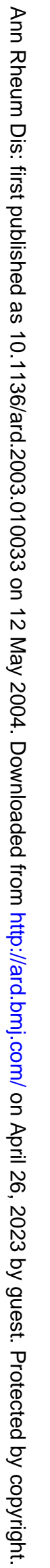


During maturation with LPS, the addition of IFN $\gamma$ further increased the secretion of IL6, TNF $\alpha$, and IL12 by DC both from patients with RA and controls.

Although the percentage increase of cytokine production by $\mathrm{mDC}$ was less than that of $\mathrm{iDC}, \mathrm{mDC}$ from patients with RA secreted enormous amounts of these cytokines, which were significantly higher than the levels secreted by DC from controls.

In strong contrast, stimulation with IFN $\gamma$ of DC clearly decreased production of IL10 by iDC and MDC from both patients with RA and healthy controls.

\section{DISCUSSION}

We have previously observed an increased expression of Fc $\gamma$ RII, probably subtype IIb, on DC from patients with RA and suggested that this might function as a counter mechanism to suppress inflammation. ${ }^{15}$ Therefore, we investigated whether this phenomenon has biological consequences. To this aim we studied the production of various proinflammatory, Th1, and Th2 cytokines by DC after triggering of Fc $\gamma R$ with IC and after Fc $\gamma R$ independent stimuli such as IFN $\gamma$. Our results clearly show that fully matured DC from patients with RA produce significantly higher levels of proinflammatory (ILl, IL6, and TNF $\alpha$ ) and Th2 (IL10) cytokines than those of healthy donors. These results are in line with previous reports, which suggest a balance towards proinflammatory cytokines and Thl responses by inflammatory cells in RA. ${ }^{8} 40$

Intriguingly, triggering of $\mathrm{F} c \gamma \mathrm{R}$, abundantly expressed on DC, resulted in clear differences in IL6 and TNF $\alpha$ production between DC from patients with RA and healthy controls. Whereas stimulation by IC in healthy subjects led to an increased production of IL6 and TNF $\alpha$, the opposite effect was observed by DC from patients with RA. That Fc $\gamma$ R triggering leads to an increased production of $\mathrm{TNF} \alpha$ by monocytes and macrophages from healthy donors has been previously reported..$^{41}{ }^{42}$ However, we are the first to describe a reversed effect in RA and suggest a different balance of activation and inhibitory Fc $\gamma$ R on DC from patients with RA in comparison with controls. As only IL6 and TNF $\alpha$ and not IL1, IL10, IFN $\gamma$, and IL12 are differentially influenced by the balance in Fc $\gamma R$ expression suggests that this is not a generalised phenomenon and might provide a new tool enabling the production of several cytokines to be tuned specifically. In agreement with recent observations, the balance of IL12 and IL10, two cytokines diametrically opposed in their function, altered dramatically upon Fc $\gamma \mathrm{R}$ stimulation on DC. ${ }^{29}{ }^{30}$ Activation of Fc $\gamma$ R led to a skewed IL12/IL10 balance towards the latter in both groups but was more pronounced in RA.

The much higher production of cytokines after stimulation with LPS or IFN $\gamma$ by DC from patients with RA is intriguing and might suggest the presence of imprinting phenomena in DC. It is well known that DC development is influenced by a plethora of environmental factors which favour distinct DC phenotypes. DC obtained from patients with RA are probably primed by a variety of stimuli such as cytokines, chemokines which are abundantly present in the serum and joints of patients with RA. ${ }^{48}$ Accumulating evidence suggests that the DC phenotype can be defined by its Thl/Th2 cytokine profile which, in turn, determines the polarisation of the $\mathrm{T}$ cell response. However, it remains a matter of debate how DC influence this decision and whether the ability to respond differently is acquired by environmental factors or is an intrinsic property. A large body of evidence points towards DC having a key role in the orchestration of the innate and adaptive immune responses. Furthermore, involvement of DC in the modulation and control of both central and peripheral tolerance is generally well established. ${ }^{1143-45}$ DC perform these pivotal functions and the expression of both inhibitory and activation $\mathrm{F} c \gamma \mathrm{R}$ is of paramount importance; this has been elegantly addressed by several studies. ${ }^{29} 4647$ Anderson $e t$ al showed that only macrophages stimulated with antigen directed to Fc $\gamma \mathrm{R}$ result in the production of antigen-specific $\mathrm{T}$ cells, which preferentially produce Th2 cytokines.$^{29}$ Moreover, the development of immunity or tolerance against tumour antigens was largely dependent on the balance between activation or inhibitory Fc $\gamma \mathrm{R} .{ }^{47}$ Additionally, the involvement of Fc $\gamma \mathrm{R}$ in synovial inflammation was clearly demonstrated in several models of experimental arthritis and RA. ${ }^{26-28} 42$ Our data might support the hypothesis that DC in RA represent a protective cell type but fail to orchestrate this protective effect to the full extent owing to an as yet unknown cause. This hypothesis is further underlined by preliminary data, which show that DC from patients with RA cannot increase the expression of Fc $\gamma$ RII to levels achieved by DC of healthy controls after certain stimuli (manuscript in preparation). Recently, genetic alterations in the regulatory regions in the Fc $\gamma$ RIIb gene were found. ${ }^{48}{ }^{49}$ However, both environmental and intrinsic factors may be implicated in determining the balance between inhibitory and activation Fc $\gamma$ R. Possibly, one or more of these potential factors is affected in RA. The profiles of cytokine production observed after Fc $\gamma$ R triggering and the differences between patients with RA and healthy controls strongly favour this hypothesis. However, an intrinsic defect cannot be excluded and is potentially reflected by the inability to fully employ their protective phenotype in vivo.

DC are preferentially located in the perivascular regions of the synovial tissue, where they fulfil an important role in the chemoattraction and instruction of other inflammatory cells. Therefore, from a therapeutic point of view, manipulation of cytokine profiles and behaviour of DC represents a very attractive strategy to orchestrate and control the autoimmunity seen in RA. The fact that our data show that triggering of Fc $\gamma R$, at least partly, overrules cytokine production in response to activation of Toll-like receptors (LPS stimulation) is highly interesting. It was suggested recently that high levels of IL6 induced by activation of Toll-like receptors block the activity of regulatory $\mathrm{T}$ cells in vivo. This phenomenon might explain the beneficial effects of intravenous immunoglobulin seen in many diseases (reviewed by Mackay and Rosen $^{51}$ ). Strong evidence for a clinical effect in RA, however, is lacking and might be due to our suggested FcrRIIb regulatory defect. ${ }^{52}{ }^{53}$ Further elucidation of the mechanisms involved in the regulation of FcrRIIb might provide new clues for the modulation of DC function in autoimmune diseases such as RA.

In summary, the present study provides strong evidence that DC may play a part in the pathogenesis of RA owing to their high production of proinflammatory and Thl cytokines, which is differentially regulated by Fc $\gamma \mathrm{R}$ on DC from patients with RA and healthy controls. More insights into these mechanisms might provide new clues about the regulation of (auto)immunity and tolerance by DC in RA and might expand our therapeutic armamentarium to control this disease.

\section{Authors' affiliations \\ T R D J Radstake, P L E M van Lent, A B Blom, P Barrera, W B van den Berg, Department of Experimental Rheumatology, University Medical Centre, Niimegen, The Netherlands \\ G J Pesman, F G J Sweep, Experimental and Chemical Endocrinology, University Medical Centre, Nijmegen, The Netherlands \\ J Rönnelid, Clinical Immunology, Autoimmunity and Allergy, University Hospital Uppsala, Sweden \\ G J Adema, Tumour Immunology Laboratory, University Medical Centre, Nijmegen, The Netherlands}




\section{REFERENCES}

1 Elliott MJ, Maini RN, Feldmann M, Kalden JR, Antoni C, Smolen JS, et al. Randomised double-blind comparison of chimeric monoclonal antibody to tumour necrosis factor alpha (CA2) versus placebo in rheumatoid arthritis. Lancet 1994;344: 1 105-10.

2 Maini RN, Breedveld FC, Kalden JR, Smolen JS, Davis D, Macfarlane JD, et al Therapeutic efficacy of multiple intravenous infusions of anti-fumor necrosis factor alpha monoclonal antibody combined with low-dose weekly methotrexate in rheumatoid arthritis. Arthritis Rheum 1998;41:1552-63.

3 Feldmann M, Maini RN. The role of cytokines in the pathogenesis of rheumatoid arthritis. Rheumatology (Oxford) 1999:38(suppl 2):3-7.

4 Isomaki P, Punnonen J. Pro- and anti-inflammatory cytokines in rheumatoid arthritis. Ann Med 1997;29:499-507.

5 Vervoordeldonk MJ, Tak PP. Cytokines in rheumatoid arthritis. Curr Rheumatol Rep 2002;4:208-17

6 Firestein GS, Boyle DL, Yu C, Paine MM, Whisenand TD, Zvaifler NJ, et al. Synovial interleukin-1 receptor antagonist and interleukin-1 balance in rheumatoid arthritis. Arthritis Rheum 1994;37:644-52.

7 van der Graaff WL, Prins AP, Dijkmans BA, van Lier RA. Prognostic value of Th1/Th2 ratio in rheumatoid arthritis. Lancet 1998;351:1931.

8 Schulze-Koops H, Kalden JR. The balance of Th1/Th2 cytokines in rheumatoid arthritis. Best Pract Res Clin Rheumatol 2001;15:677-91.

9 Lanzavecchia A, Sallusto F. Regulation of T cell immunity by dendritic cells. Cell 2001;106:263-6.

10 Mellman I, Steinman RM. Dendritic cells: specialized and regulated antigen processing machines. Cell 2001;106:255-8.

11 Steinman RM, Nussenzweig MC. Inaugural article: avoiding horror autotoxicus: The importance of dendritic cells in peripheral T cell tolerance. Proc Natl Acad Sci USA 2002;99:351-8.

12 Leung BP, Conacher M, Hunter D, Mclnnes IB, Liew FY, Brewer JM. A nove dendritic cell-induced model of erosive inflammatory arthritis: distinct roles for dendritic cells in T cell activation and induction of local inflammation. $J$ Immunol 2002; 169:7071-7.

13 Li TF, Mandelin J, Hukkanen M, Lassus J, Sandelin J, Santavirta S, et al. Dendritic cells in rheumatoid synovial membrane after total removal of the hyaline articular cartilage. Rheumatology (Oxford) 2002;41:319-23.

14 Page G, Lebecque S, Miossec P. Anatomic localization of immature and mature dendritic cells in an ectopic lymphoid organ: correlation with selective chemokine expression in rheumatoid synovium. J Immunol 2992; 168:5333-41.

15 Radstake TR, Blom AB, Sloetjes AW, van Gorselen EO, Pesman GJ, Engelen L, et al. Elevated Fc $\gamma \mathrm{Rll}$ expression and aberrant TNF- $\alpha$ production by mature DCS of patients with active rheumatoid arthritis (RA). Ann Rheum Dis (in press).

16 Tokayer A, Carsons SE, Chokshi B, Santiago-Schwarz F. High levels of interleukin 13 in rheumatoid arthritis sera are modulated by tumor necrosis factor antagonist therapy: association with dendritic cell growth activity. J Rheumatol 2002;29:454-61.

17 Tsark EC, Wang W, Teng YC, Arkfeld D, Dodge GR, Kovats S. Differential MHC class II-mediated presentation of rheumatoid arthritis autoantigens by human dendritic cells and macrophages. J Immunol 2002; 169:6625-33.

18 Amigorena S, Bonnerot C. Fc receptor signaling and trafficking: a connection for antigen processing. Immunol Rev 1999;172:279-84

19 Fanger NA, Wardwell K, Shen L, Tedder TF, Guyre PM. Type I (CD64) and type II (CD32) Fc gamma receptor-mediated phagocytosis by human blood dendritic cells. J Immunol 1996;157:541-8.

20 Bell D, Young JW, Banchereau J. Dendritic cells. Adv Immuno 1999:72:255-324.

21 Pettit AR, MacDonald KP, O'Sullivan B, Thomas R. Differentiated dendritic cells expressing nuclear RelB are predominantly located in rheumatoid synovial tissue perivascular mononuclear cell aggregates. Arthritis Rheum 2000;43:791-800.

22 Dijstelbloem HM, van De Winkel JG, Kallenberg CG. Inflammation in autoimmunity: receptors for lgG revisited. Trends Immunol 2001;22:510-16.

23 Salmon JE, Pricop L. Human receptors for immunoglobulin G: key elements in the pathogenesis of rheumatic disease. Arthritis Rheum 2001;44:739-50.

24 Leadbetter EA, Rifkin IR, Hohlbaum AM, Beaudette BC, Shlomchik MJ, Marshak-Rothstein A. Chromatin-lgG complexes activate B cells by dua engagement of IgM and Toll-like receptors. Nature 2002;416:603-7.

25 Mannik M, Nardella FA, Sasso EH. Rheumatoid factors in immune complexe of patients with rheumatoid arthritis. Springer Semin Immunopathol 1988; 10:215-30.

26 Blom $\mathbf{A B}$, van Lent $\mathrm{PL}$, van Vuuren $\mathrm{H}$, Holthuysen $A E$, Jacobs $C$, van de Putte $L B$, et al. FcgammaR expression on macrophages is related to severity and chronicity of synovial inflammation and cartilage destruction during experimental immune-complex-mediated arthritis (ICA). Arthritis Res 2000;2:489-503.

27 van Lent $P L$, van Vuuren $A J$, Blom $A B$, Holthuysen $A E$, van de Putte $L B$, van de Winkel JG, et al. Role of Fc receptor gamma chain in inflammation and cartilage damage during experimental antigen-induced arthritis. Arthritis Rheum 2000;43:740-52.

28 van Lent PL, Nabbe K, Blom AB, Holthuysen AE, Sloetjes A, van de Putte LB, et al. Role of activatory Fc gamma RI and Fc gamma RIII and inhibitory Fc gamma RIl in inflammation and cartilage destruction during experimental antigen-induced arthritis. Am J Pathol 2001;159:2309-20.

29 Anderson CF, Mosser DM. Cutting edge: biasing immune responses by directing antigen to macrophage Fcgamma receptors. J Immunol 2002;168:3697-701.

30 Anderson CF, Mosser DM. A novel phenotype for an activated macrophage: the type 2 activated macrophage. J Leukoc Biol 2002;72:101-6.

31 Morita Y, Yang J, Gupta R, Shimizu K, Shelden EA, Endres J, et al. Dendritic cells genetically engineered to express IL- 4 inhibit murine collagen-induced arthritis. J Clin Invest 2001;107:1275-84.

32 Kim SH, Kim S, Evans CH, Ghivizzani SC, Oligino T, Robbins PD. Effective treatment of established murine collagen-induced arthritis by systemic administration of dendritic cells genetically modified to express IL-4. J Immunol $2001 ; 166: 3499-505$

33 Arnett FC, Edworthy SM, Bloch DA, McShane DJ, Fries JF, Cooper NS, et al. The American Rheumatism Association 1987 revised criteria for the classification of rheumatoid arthritis. Arthritis Rheum 1988;31:315-24

34 Geijtenbeek TB, Torensma R, van Vliet SJ, van Duijnhoven GC, Adema GJ van Kooyk Y, et al. Identification of DCS-SIGN, a novel dendritic cell-specific ICAM-3 receptor that supports primary immune responses [see comments]. Cell 2000;100:575-85

35 Van Der Meer JW, Endres S, Lonnemann G, Cannon JG, Ikejima T, Okusawa $\mathrm{S}$, et al. Concentrations of immunoreactive human tumor necrosis factor alpha produced by human mononuclear cells in vitro.

36 Drenth JP, Van Uum SH, van Deuren M, Pesman GJ, Van der VenJongekriig J, Van Der Meer JW. Endurance run increases circulating IL-6 and IL-1 ra but downregulates ex vivo TNF-alpha and IL-1 beta production. J Appl Physiol 1995:79:1497-503.

37 Helle M, Boeije L, de Groot E, de Vos A, Aarden L. Sensitive ELISA for interleukin-6. Detection of IL- 6 in biological fluids: synovial fluids and sera. J Immunol Methods 1991;138:47-56.

38 Rönnelid J, Tejde A, Mathsson L, Nilsson-Ekdahl K, Nilsson B. Immune complexes from SLE sera induce IL10 production from normal periphera blood mononuclear cells by an FcgammaRIl dependent mechanism: implications for a possible vicious cycle maintaining B cell hyperactivity in SLE. Ann Rheum Dis 2003;62:37-42.

39 Grebenschikov N, Geurts-Moespot A, De Witte H, Heuvel J, Leake R, Sweep F, et al. A sensitive and robust assay for urokinase and tissue-type plasminogen activators (UPA and TPA) and their inhibitor type I (PAI-1) in breast tumor cyłosols. Int J Biol Markers 1997;12:6-14.

40 Arend WP. Cytokine imbalance in the pathogenesis of rheumatoid arthritis: the role of interleukin-1 receptor antagonist. Semin Arthritis Rheum 2001;30(suppl 2):1-6

41 Abrahams VM, Cambridge G, Lydyard PM, Edwards JC. Induction of tumor necrosis factor alpha production by adhered human monocytes: a key role for Fcgamma receptor type Illa in rheumatoid arthritis. Arthritis Rheum 2000;43:608-16

42 Blom AB, Radstake TR, Holthuysen AE, Sloetjes A, Pesman GJ, Sweep CG, et al. Increased expression of F $\gamma$ RIl and III expression on macrophages of RA patients results in higher TNF $\alpha$ and MMP production. Arthritis Rheumatism 2003:48:1002-14

43 Jonuleit H, Schmitt E, Steinbrink K, Enk AH. Dendritic cells as a tool to induce anergic and regulatory T cells. Trends Immunol $2001 ; 22: 394-400$.

44 Lu L, Thomson AW. Manipulation of dendritic cells for tolerance induction in transplantation and autoimmune disease. Transplantation 2002;73(suppl):S19-S22.

45 Pulendran B, Banchereau J, Maraskovsky E, Maliszewski C. Modulating the immune response with dendritic cells and their growth factors. Trends Immunol $2001 ; 22: 41-7$.

46 Clynes R, Maizes JS, Guinamard R, Ono M, Takai T, Ravetch JV. Modulation of immune complex-induced inflammation in vivo by the coordinate expression of activation and inhibitory Fc receptors. J Exp Med 1999;189:179-85.

47 Kalergis AM, Ravetch JV. Inducing tumor immunity through the selective engagement of activating Fcgamma receptors on dendritic cells. J Exp Med 2002;195:1653-9

48 Jiang Y, Hirose S, Abe M, Sanokawa-Akakura R, Ohtsuji M, Mi X, et al. Polymorphisms in lgG Fc receptor IIB regulatory regions associated with autoimmune susceptibility. Immunogenetics 2000;51:429-35.

49 Yasuda K, Sugita N, Yamamoto K, Kobayashi T, Yoshie H. Seven single nucleotide substitutions in human Fc $\gamma$ receptor IIB gene. Tissue Antigens 2001;58:339-42.

50 Pascare C, Medzhitov R. Toll pathway-dependent blockade of CD4+CD25+ T cell-mediated suppression by dendritic cells. Science 2003;299:1033-6.

51 Mackay I, Rosen F. Immunomodulation of autoimmune and inflammatory diseases with intravenous immune globulin. N Engl J Med 2001;345:747-55.

52 Kanik K, Yarbora C, Naparstek Y, Plots P, Wilder R. Failure of low-dose intravenous immunoglobulin therapy to suppress disease activity in patients with treatment-refractory rheumatoid arthritis. Arthritis Rheum 1996;39: 1027-29.

53 Maksymowych W, Avina-Zubieta A, Luong M, Russell A. High dose intravenous immunoglobulin (IVlg) in severe refractory rheumatoid arthritis: no evidence for efficacy. Clin Exp Rheumatol 1996;14:657-60. 